\title{
O CICLO PDCA NA TOMADA DE DECISÃO
}

\author{
THE PDCA CYCLE IN DECISION MAKING
}

\begin{abstract}
Hector Aparecido Bemi - hector_bemi@hotmail.com Faculdade de Tecnologia de Taquaritinga - Taquaritinga - São Paulo - Brasil

Marco Antônio Alves de Souza Junior - marco.adm90@gmail.com Faculdade de Tecnologia de Taquaritinga - Taquaritinga - São Paulo - Brasil

DOI: 10.31510/infa.v18i1.1088

Data de submissão: 16/03/2021

Data do aceite: 09/07/2021

Data da publicação: 30/07/2021
\end{abstract}

\section{RESUMO}

O objetivo desse artigo é utilizar o ciclo PDCA no planejamento de processos produtivos e com isso obter melhores respostas nas tomadas de decisões. Neste estudo foi utilizado esta ferramenta para identificação e tomada de decisões para solucionar perdas que ocorreram nos métodos de produção da empresa. Foi também utilizado o embasamento teórico com pesquisas bibliográficas, onde foi comprovado a eficiência e importância do uso do ciclo PDCA e quanto contribui para as organizações.

Palavras-chave: PDCA, Produtividade, Gestão da qualidade, Ferramentas de gestão.

\begin{abstract}
The purpose of this article is to use the PDCA cycle in the planning of production processes and thereby obtain better responses in decision-making. In this study, this tool was used to identify and make decisions to solve losses that occurred in the company's production methods. Theoretical basis with bibliographic research was also used, where the efficiency and importance of the use of the PDCA cycle and how much it contributes to organizations was proven.
\end{abstract}

Keywords: PDCA, Productivity, Quality management, Management tools.

\section{INTRODUÇÃO}

Para Vieira Filho (2010, p. 24) o PDCA é um método que coordena as tomadas de decisões visa sempre melhorar as atividades de uma organização também, muito explorado na 
busca da melhoria contínua e da performance. Sendo assim a feramente PDCA é de extrema importância e contribui grandemente para a obtenção dos melhores resultados.

O Ciclo PDCA, também conhecido como Ciclo de Shewhart, Ciclo da Qualidade ou Ciclo de Deming, é uma metodologia que tem como função básica o auxílio no diagnóstico, análise e prognóstico de problemas empresariais, é extremamente útil para a solução de problemas e tomada de decisões. Poucos instrumentos se mostram tão efetivos para a busca do aperfeiçoamento quanto este método de melhoria contínua, tendo em vista que ele conduz a ações sistemáticas que agilizam a obtenção de melhores resultados com a finalidade de garantir a sobrevivência e o crescimento das organizações, (QUINQUIOLO, 2002).

Atualmente nas indústrias metalmecânica, a fundição é o processo de fabricação inicial de todo o processo produtivo, podendo ter ou não usinagem posterior. A usinagem é um processo de fabricação muito importante, pois ela pode ser usada como fase final ou intermediária na produção de produtos industrializados. Existem defeitos que vem da fundição, que impactam diretamente na qualidade do fundido, quando passa pela usinagem podem tornar-se refugo devido o defeito causado pela fundição, como ou por exemplo a porosidade na superfície da peça fundida. E um processo produtivo de usinagem, peças foram encontradas com porosidades, ocasionando refugo e defeitos superficiais onde gerou atraso na produção.

Neste caso a utilização de ferramenta de gestão para o controle de qualidade, controle da produção são indispensáveis para auxiliar nos melhores caminhos a seguir e métodos de gerir as perdas nos processos industriais de produção. Além de obter clareza no que se precisa mensurar.

A ferramenta de gestão PDCA teve suma importância na tomada de decisões e solução dos problemas apresentados pois foi possível mensurar de maneira qualitativa, as perdas no processo de produção. Realizou-se o levantamento dos custos, e quantidade de refugo. Foi adotado novos métodos de auxilio no controle de qualidade para facilitar na apuração dos dados.

Este trabalho teve como objetivo, demonstrar a importância do uso da ferramenta PDCA nas tomadas de decisões. Como tratou - se de um estudo de casos, foi de extrema relevância a utilização desta ferramenta na empresa onde se aplicou o estudo. O planejamento estratégico da empresa em relação aos defeitos que vem dos fornecedores, adotando novos métodos e caminhos para seguir com o uso desta ferramenta. Onde é possível gerir o melhor 
caminho a seguir tendo as melhores decisões a serem tomadas e levantamento dos dados obtidos durante a utilização da ferramenta.

\section{FUNDAMENTAÇÃO TEÓRICA}

Em geral as empresas não devem preocupar-se somente com o controle de sua a produtividade, mas também com a não conformidade dos produtos, pois os mesmos podem influenciar de maneira significante no rendimento mensal. Sendo que muitas das vezes os produtos que apresentam a não conformidade, acabam escondendo o real valor, por gerar retrabalhos ou refugos em seus produtos.

Segundo a norma NBR ISO 9001 (2008) 8.3, a empresa deve certificar - se que os produtos sejam produzidos seguindo os requisitos exigidos. Devem ser identificados e passar por controle par que possa ser evitado o uso ou entrega não desejada. Os produtos com não conformidade não dever ser misturados com os produtos conformes, pois caso isso venha a acontecer, irá acarretar para a empresa perda no processo produtivo, geração de custo, e demais envolvimentos no processo produtivo.

De acordo com a norma NBR ISO 9001 (2008, p.13), a organização deve tratar os produtos não conformes por uma ou mais das seguintes formas:
a) Execução de ações para eliminar a não conformidade detectada;
b) Autorização do seu uso, liberação ou aceitação sob concessão por uma autoridade pertinente e, onde aplicável, pelo cliente;
c) Execução de ação para impedir o seu uso pretendido ou aplicação originais;
d) Execução de ações apropriadas aos efeitos, ou potenciais, da não
conformidade quando o produto não conforme for identificado após entrega ou início do uso do produto.

Logo após a identificação do erro, a ação para correção deve ser tomada em seguida. Ainda pode - se utilizar do erro cometido para - se iniciar um processo de melhorias contínuas no processo de processo de produção e fabricação dos produtos, evitando perdas e custo. Para assegurar uma gestão da qualidade melhorada de forma constante, utiliza - se a norma NBR ISO 9001 (2008) item 8.5.1 a organização deve continuamente melhorar a eficácia do sistema de gestão da qualidade por meio do uso da política da qualidade, objetivo da qualidade, resultados de auditorias, análise de dados, ações corretivas e preventivas e análise crítica pela direção. A norma explica como se deve agir na empresa, senso tudo 
reunido e explanado de maneira interna. A melhoria contínua deve ser aplicada em todos os departamentos da empresa, desde o chão de fábrica até a alta direção, tendo assim como benefícios a padronização e otimização de métodos e processos de todos os envolvidos.

\subsection{Ciclo PDCA}

O Ciclo PDCA, também conhecido como Ciclo de Shewhart, Ciclo da Qualidade ou Ciclo de Deming, é uma metodologia que tem como função básica o auxílio no diagnóstico, análise e prognóstico de problemas organizacionais, sendo extremamente útil para a solução de problemas. Poucos instrumentos se mostram tão efetivos para a busca do aperfeiçoamento quanto este método de melhoria contínua, tendo em vista que ele conduz a ações sistemáticas que agilizam a obtenção de melhores resultados com a finalidade de garantir a sobrevivência e o crescimento das organizações (QUINQUIOLO, 2002).

O ciclo PDCA foi desenvolvido originalmente por Walter Shewart, na década de 1920, mas ganhou notoriedade com Edwards Deming na década de 1950. Oeming é autor dos famosos princípios do Gerenciamento da Qualidade Total (TQM). Alguns deles são: - deve liaver constância de propósitos para a melhoria do produto e do serviço; • A qualidade do produto nasce no estágio inicial; • as pessoas devem trabalharem equipe, sem barreiras entre os departamentos, de modo que possam prever problemas e soluções; • O processo de melhoria é de competência de todos. (MATTOS; 2010, p.37)

Seguindo o conceito de Mattos (2010; p. 38 - 40), a etapa P (planejar), está subdividida em três setores dentre eles:

- Estudar o projeto, visa fazer a análise dos projetos, e vista técnica na obra para fazer identificações e avaliações.

- Definir metodologia, deve envolver os processos da construção, planejamento da abra envolvendo todos os setores desde o produtivo ao burocrático.

- Gerar o cronograma e as programações, quantificar as etapas do andamento da obra seguindo o cronograma de atividades.

A segunda etapa D (desempenhar), tem como função por em pratica todo o planejamento. Treinar toda a equipe envolvida, fazer a apuração dos dados para avaliação posterior, elaborar um plano de ação e cronograma de atividade:

- Informar e motivar, explanação para todos envolvidos nas sequencias de atividades e reuniões para dúvidas e planejamento. É realizado um treinamento a fim de mostrar os prazos inseridos e programação das tarefas envolvidas. 


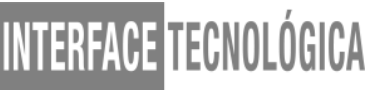

- Executar a atividade, realização a atividade, gerenciamento, planejamento a fim de cumprir o que está previsto no planejamento no determinado período.

A terceira etapa C (checar), consiste na comparação no que está previsto com o seguimento da realização, apontando um monitoramento e controle do projeto.

- Aferir o realizado, fazer levantamento por meio de uma análise, aprimorando os dados, compilando as quantidades já desenvolvidas.

- Comparar o previsto e o realizado.

A quarta etapa A (agir), ocorre nesta etapa as trocas e opiniões e sugestões, de toda a equipe evolvida na operação. É de suma importância, a identificação de possíveis melhorias, e aperfeiçoamento. Sendo necessário também o envolvimento do departamento de produção e planejamento do projeto nesta etapa.

\subsection{Diagrama de Ishikawa}

Outra ferramenta muito utilizada para a gestão de qualidade ó o diagrama de Ishikawa. Onde é utilizado para visualizar as causas principais e secundárias para um problema e o efeito que causado.

O fluxo dos materiais na organização se inicia com o contato inicial com o fornecedor, sendo até a efetivação da entrega dos produtos ao cliente ou consumidor final. Nesta movimentação engloba todas as funções de compras, planejamento, e controle da produção e distribuição. Sendo assim exigindo um fluxo funcional de informações e conformação com as necessidades dos clientes. (Christopher, 1999).

Seguindo Viana (2002) os recursos financeiros são determinados como todos os recursos à disposição que esteja de alguma maneira relacionada com o capital ou dinheiro. As organizações são necessárias diversos recursos para execução de suas operações. Dentre estes recursos, estes são os fatores humanos, que são constituídos por toda operação dentro da empresa que esteja envolvida de alguma forma com a atividade humana no meio empresarial.

De acordo com Martins e Alt (2000) a administração das ferramentas vem com um desenvolvimento através da utilização de ferramentas de gerenciamento. Esta pratica de uso 


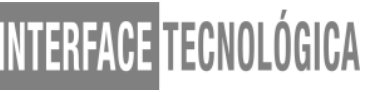

empenha-se nas situações, onde os recursos apresentam gradativamente menores, sendo desde o gerenciamento palpável para prestações de serviços.

Conforme Viana (2002) coordenar os recursos e materiais é uma função que tem como responsabilidades a busca dos melhores resultados visando a lucratividade e produtividade, mantendo sempre a constante conformidade com o cliente. O administrador deve controlar os processos da organização, orientando e mostrando os caminhos a seguir as rotinas de trabalho, fazendo uma gestão de forma eficaz, utilizando os equipamentos, material, serviços e capital, sempre da melhor forma nos processos envolvidos. Para o autor, as empresas disponibilizamse de vários e deferentes tipos de recursos para a realização das suas operações, sendo que os recursos está o recurso financeiro, que constitui em todos os aspectos as execuções da empresa que estejam envolvidas com capital.

\section{PROCEDIMENTOS METODOLÓGICOS}

\subsection{Materiais e Métodos}

Foi realizado um estudo sobre aplicação da ferramenta PDCA em empresa de bombas centrifugas no estado de SP, fazendo um levantamento de dados que causaram o refugo. Todos os dados foram levantados através das ferramentas de gestão da produção e qualidade.

O estudo foi realizado de forma quantitativa, onde mensurou - se os dados por coleta através de preenchimento de documentos e planilhas, mensurando os dados através do preenchimento de formulários, expressando graficamente os dados obtidos.

Para Fonseca (2002 p. 20), os resultados da pesquisa quantitativa podem ser quantificados. Como as amostras e coleta de dados, geralmente são grandes e consideradas representativas para servir de parâmetros.

Os resultados são tomados como se constituíssem um retrato real de toda a população alvo da pesquisa. A pesquisa quantitativa se centra na objetividade recorre à linguagem matemática para descrever as causas de um fenômeno, as relações entre variáveis. A utilização conjunta da pesquisa qualitativa e quantitativa permite recolher mais informações do que se poderia conseguir isoladamente.

A Indústria de bombas em seu parque fabril tem tecnologia e equipamentos de última geração para desenvolver e produzir as melhores soluções em Bombas Centrífugas e 


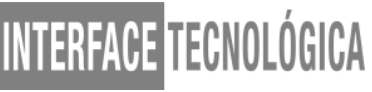

Autoescorvante, para atender os mais variados projetos de Irrigação Agrícola, Combate a Incêndio, Caminhão Pipa e Carreta Tanque Agrícola.

Adotou-se como forma inicial, o uso de formulários chamados de RNC (Registro de Não Conforme) de levantamento, para identificar os motivos dentro da cadeia de produção que causou as perdas. Os formulários são auxiliados pelo PDCA, onde começa com o PLANEJAMENTO $(\mathrm{P})$ de fazer o mapeamento e identificação de quais são as peças que apresenta defeito e quem são os fornecedores, e por quais equipamentos a peça irá percorrer.

Ainda em utilização da ferramenta atuou-se com a AÇÃO (D), onde são notificados os fornecedores que tomaram o conhecimento das peças não conformes causadas pela porosidade. Então fez a CHEGAGEM (C) dos métodos empregados, e efetivação dos mesmos. Os métodos empregados foram, formulários de registro não conforme (RNC) e SANC. Foi utilizado também o ciclo PDCA, desde o início da tomada de decisões.

Por fim AGIR (A), após coletar os dados e identificar os problemas, deu-se início às tomadas de decisões, fazendo as notificações dos fornecedores e gerando os protocolos de novos métodos de melhorias.

Preencher e arquivar documento da não conformidade (RNC), documento de uso interno para controle de peças não conforme e externo para que o fornecedor tenha conhecimento dos defeitos. É utilizado pela qualidade para fazer levantamento mensal, e quantificar os defeitos internos e externos.

\section{RESULTADOS E DISCUSSÃO}

\subsection{Identificação do refugo}

As peças fundidas são de origem de terceiros, ao chega na fábrica de bombas centrífugas onde foi realizado o estudo, as peças passam pelos processos de fabricação. Após a fundição as peças brutas como são chamadas, são destinadas para as fases de processo de fabricação sendo elas, fresamento, torneamento, furação e pintura. Antes de iniciar o processo de usinagem as peças são pré-avaliadas de possíveis avarias ou defeitos providos da fundição. Em seguida é possível observar nas figuras os defeitos causados pela porosidade.

As peças passaram pelo processo de usinagem chamado torneamento. Ao passar por este processo, as mesmas apresentaram irregularidades superficiais, que são chamadas de 


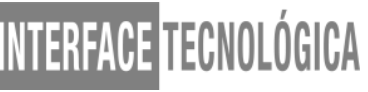

porosidade. Foram recolhidas da produção as peças que apresentaram este defeito e levadas ao departamento de qualidade. $\mathrm{O}$ inspetor de qualidade fez a avaliação das peças, chegando à conclusão que não poderiam ser utilizadas pois este tipo de defeito é prejudicial ao produto final, causando queda de rendimento das bombas centrifugas e perca de rendimento. Visando sempre a qualidade a empresa onde foram realizados os estudos, visa manter uma constante conformidade nos elementos as peças que serão utilizadas para montar o produto final.

As peças são fundidas em caixa de areia verde com machos em coldbox. Para avaliação dos resultados as peças necessitam, passar pelo processo de usinagem. Iniciando a fabricação das peças elas passam pelo processo de fresagem, onde é feito o rasgo de chaveta, o rasgo de chaveta é aberto através da ferramenta de aço rápido, com lubrificação de óleo solúvel sintético. Logo após o processo de fresagem, entra em ação o torneamento que é feito pelo torno CNC GL ROMI, á uma rotação entre 4 a 4.500 RPM. Foram utilizados insetos cerâmicos para fazer o desbaste, usinagem sem lubrificação, foi utilizada uma velocidade de corte de $800 \mathrm{~m} / \mathrm{min}$.

Ao passar pelo processo de usinagem notou - se a presença de porosidade nas peças, conforme a Figura 1,2 e 3. A porosidade é um defeito comum no processo de fundição, trata se dá solubilidade do hidrogênio no metal fundido, é necessário ser evitado para que não venha a causar defeitos nas peças fundidas. Ao identificar o defeito algumas pelas que serviram para fazer amostra, foram analisadas no laboratório de qualidade onde foi analisa as fraturas nas pelas e as marcas de poros. Ao obter a conclusão de que o defeito originou - se da fundição, realizou - se um levantamento junto a coordenação de quantas peças seriam refugadas. A coordenação da produção junto a supervisão, fez a análise utilizando a ferramenta PDCA, para que pudesse tomar as direções e as coordenadas necessárias para solução do problema. Foram feitas notificações e envidas ao fornecedor notificando. 
Figura 1- Marca de porosidade superficial após processo de usinagem

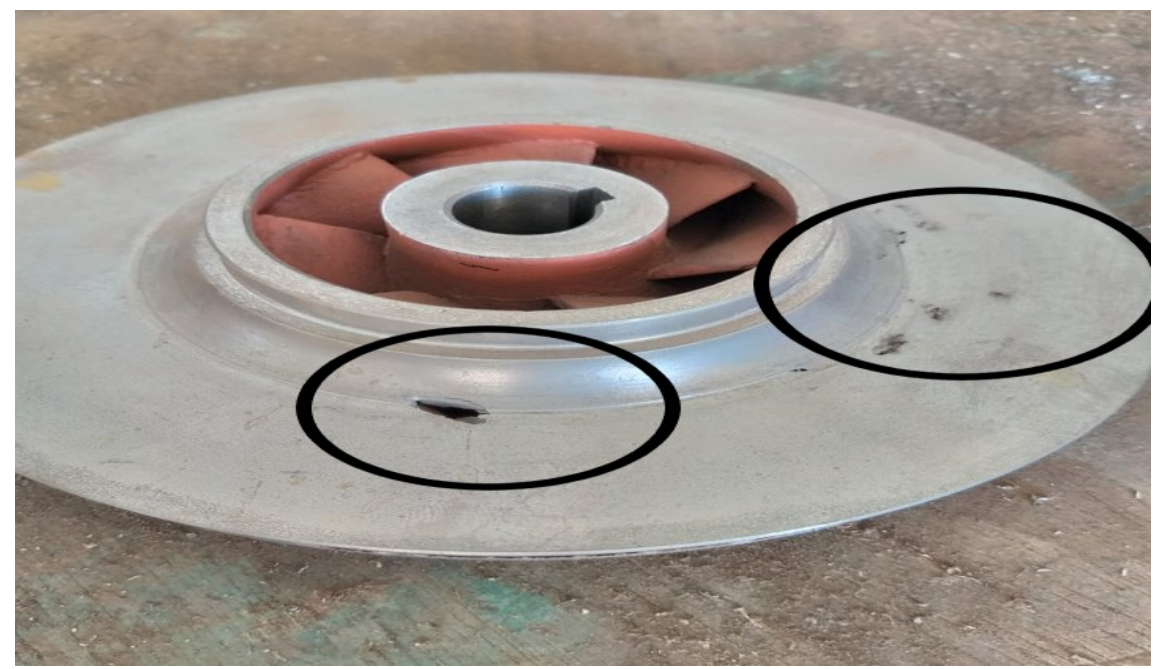

Fonte: Autores (2020)

Figura 2 - Quebra de superfície devido porosidade interna.

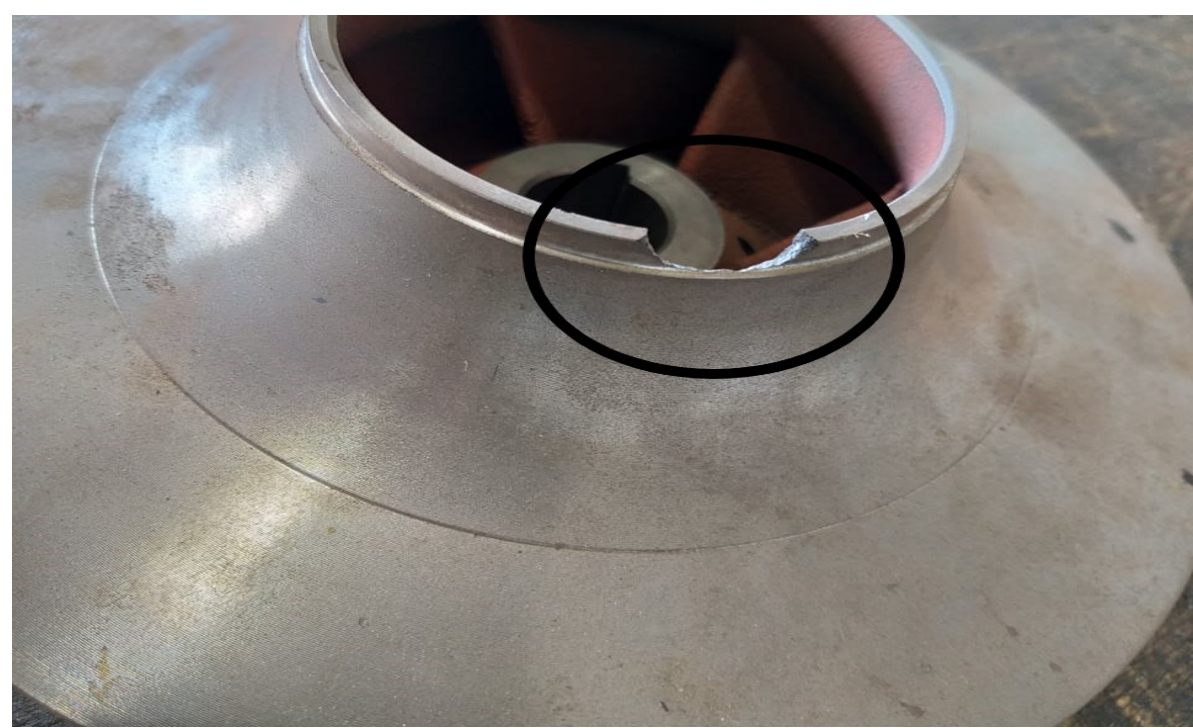

Fonte: Fonte: Autores (2020) 
Figura 3 - Porosidade superficial

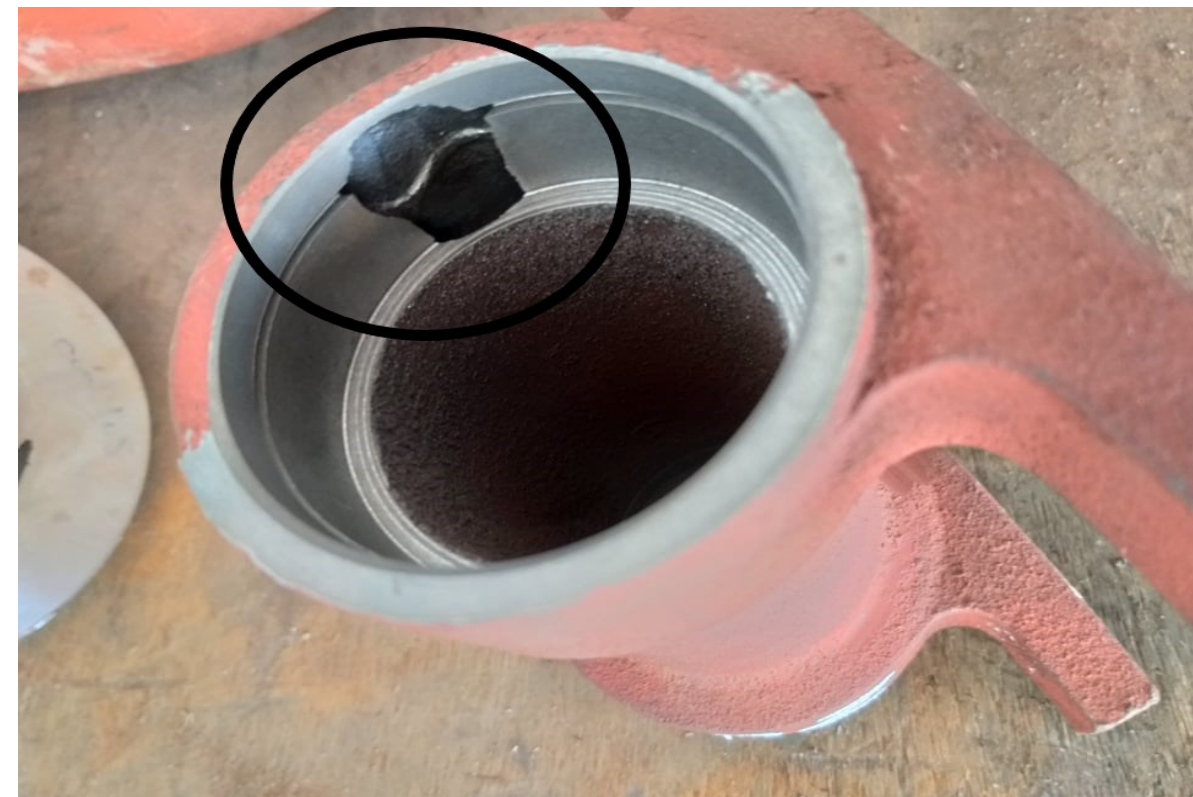

Fonte: Autores (2020)

\subsection{Ferramenta PDCA}

Após serem encontradas peças com porosidades superficiais, foi comunicado o departamento de qualidade para fazer averiguação do refugo. As peças que apresentaram este tipo de defeito foram segregadas, para preenchimento da RNC (Registro de Não Conformidade), onde o fornecedor das peças fundidas serão notificadas. Foi realizada a devolução do lote que apresentou este problema. Foi utilizada a ferramenta PDCA para conter e solucionar o problema.

\section{Planejamento:}

Identificação: Foram identificas peças com muita porosidade, inutilizando as peças para o processo produtivo, gerando refugo e atraso no processo produtivo.

$>$ Observação: Após as peças passarem pelo processo de usinagem, as mesmas apresentaram porosidade superficial, e tricas externas. 


\section{WTEERFACETEECNOLÓGiCA}

Análise: A porosidade pode levar a quebra do produto em sua utilização e vazamento quando submetida aos esforços de pressão.

Plano de ação: Os operadores foram treinados e orientados a fazer prévia inspeção do lote antes de iniciar o processo, e a qualidade fará ensaios mecânicos com os produtos antes de chegarem na usinagem.

\section{Desenvolvimento:}

Execução: Será feito o repasse das peças para o fornecedor sempre que houver uma não conformidade dos intens.

\section{Checagem:}

Verificação: Preenchimento da RNC, arquivada a documentação e enviada ao fornecedor.

Ação:

Padronização: Separação e segregação de todas as peças que apresentarem qualquer tipo de defeito ou avaria, tento como ação efetiva.

\subsection{Apresentação gráfica do índice de refugo.}

\section{Gráfico 1 - Índice de refugo por item}

\% TOP 10 Refugos - Curva ABC

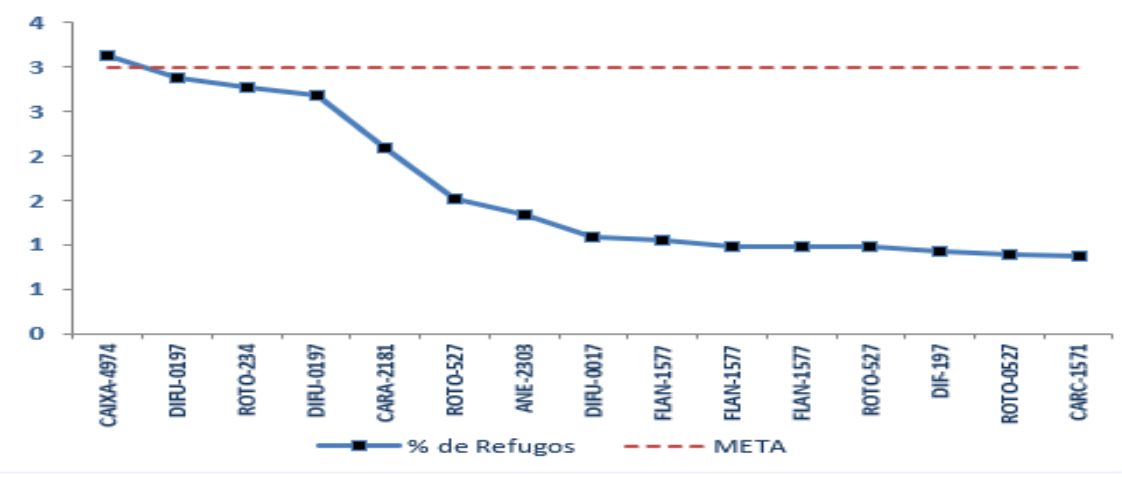

Fonte: Autores (2020) 


\section{Gráfico 2 - Custo da qualidade}

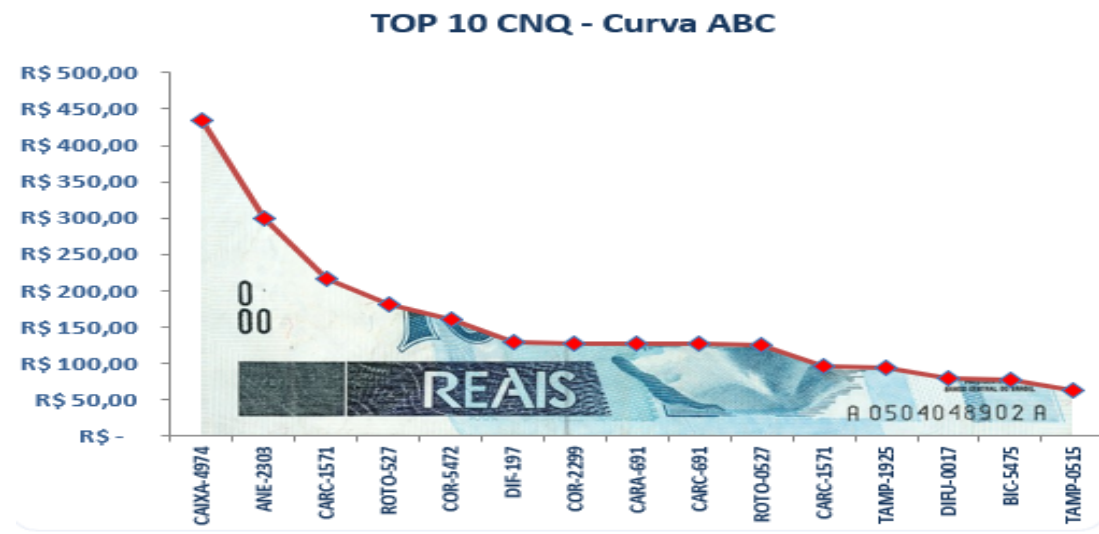

Fonte: Autores (2020)

Depois da aplicação da ferramenta PDCA, foi possível obter um maior direcionamento, nas tomadas de decisão. Ao chegar as peças da fundição é feita uma inspeção de todo o lote, o mesmo sendo aprovado pela qualidade inicia o processo de produção.

Durante o processo as peças são acompanhadas dos cartões para identificação da fase atual, o mesmo percorre junto à peça até a expedição e aprovação final. Caso apresente defeito no ato da chegada ou durante o processo, a mesma e segregada com cartão vermelho de reprovação e é enviada para segregação onde fica aos cuidados da qualidade. Junto com a supervisão que toma conhecimento da ocorrência e inicia - se o preenchimento dos documentos.

Cartões de identificação, são utilizados para separação das peças que apresentam não conformidades. São utilizados para fazer a separação e identificação com maior organização. Como apresentado na Figura 4 e 5, todos os campos são preenchidos para melhor rastreabilidade. 


\section{Figura 4 - Cartão Reprovado}

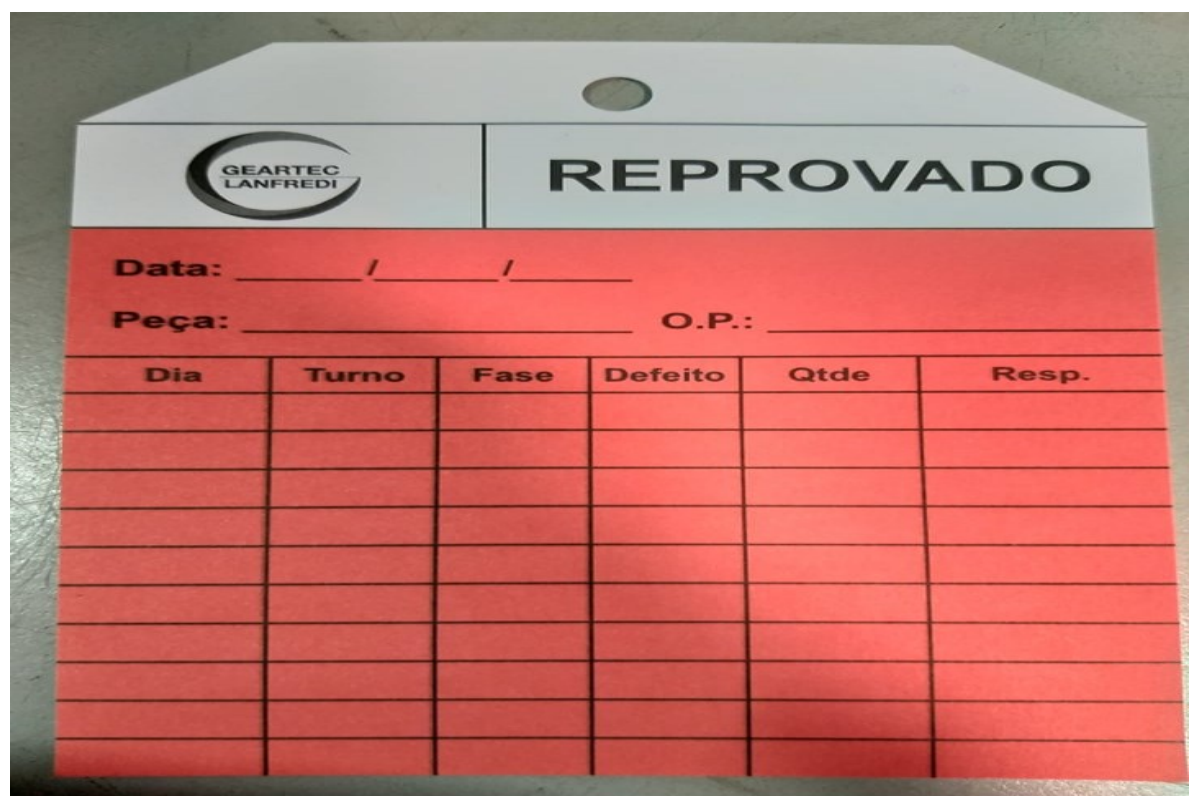

Fonte: Autores (2020)

Cartão de identificação, acompanha junto a peça a ser produzida até o ciclo final (montagem ou embalagem). Facilitando o rastreio, e em caso de não conformidade é anexado junto ao documento de RNC.

Figura 5 - Cartão identificação

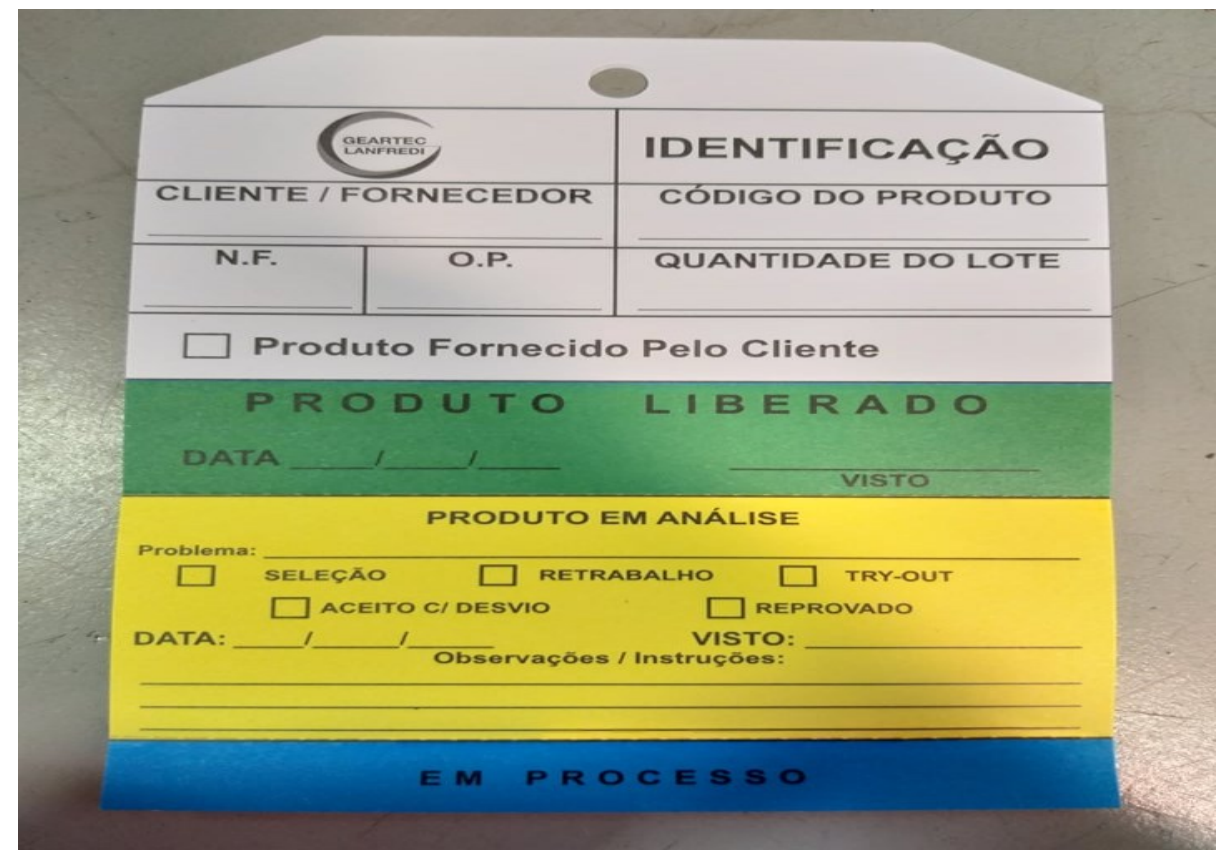

Fonte: Autores (2020)

Interface Tecnológica - v. 18 n. 1 (2021) 


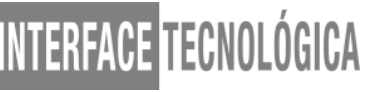

A administração de produção com a utilização de cartões tem essa grande importância, por tratar- se de um sistema de produção enxuta. Trata - se de uma ferramenta que contém informações, do processo ou fase na qual o produto se encontra. Onde é possível também obter uma maior simplificação do trabalho admirativo, por ser fácil aplicação e fácil compreensão.

\section{CONSIDERAÇÕES FINAIS}

Este trabalho foi realizado na empresa de bombas hidráulica Geartec, na cidade de Monte Alto - SP. Teve como objetivo, fazer um levantamento de dados dos problemas causados por peças fornecidas por terceiros na qual apresentaram defeito. Foi avaliado o quanto teve de impacto na produção, levantando o índice de refugo, perdas e atrasos no processo produtivo, e quais seriam os novos métodos empregados para melhor coordenar o recebimento de matéria-prima. Tendo como base a ferramenta de gestão PDCA, através desta ferramenta foi possível as tomadas de decisões.

Após o estudo com a ferramenta PDCA, onde apontou as possíveis falhas e possíveis melhorias, foram adotados alguns documentos que circulam junto à produção para melhor controle e apontamentos dos índices tais como; registro de não conformidade (RNC) é preenchido pelo inspetor de qualidade onde é registrado qualquer tipo de ocorrência que ocorra com o produto em processo caso seja defeito de terceiro logo o mesmo é notificado, caso seja interno irá para área de segregação.

Em caso de peças acabadas utiliza-se o documento (SANC), as peças são fornecidas ao cliente, as mesmas apresentarem defeito este documento faz o rastreio dos processos para identificar em qual fase ocorreu a falha.

Cartão reprovado: Acompanha a peça junto na área de segregação para analise do defeito junto ao inspetor de qualidade. O Cartão de identificação, percorre junto com o produto todas as fases do processo produtivo para facilitação do rastreio do produto.

\section{REFERÊNCIAS}

ASSOCIAÇÃO BRASILEIRA DE NORMAS TÉCNICAS (ABNT). NBR ISSO 9001:2008. Sistemas de Gestão da Qualidade. Requisitos: apresentação Rio de Janeiro: ABNT, 2018, 28 p. 


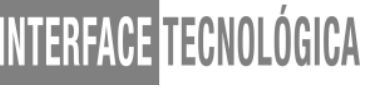

CHRISTOPHER, M. Logística gerencial da cadeia de suprimentos; e estratégias para a redução de custos e melhoria de serviços. São Paulo, Pioneira, 1999.

FONSECA, J. S. Metodologia da pesquisa científica. Fortaleza; UEC; 2002. Apostila.

QUINQUIOLO, J. M. Avaliação da Eficácia de um Sistema de Gerenciamento para Melhorias Implantado na Área de Carroceria de uma Linha de Produção Automotiva. TaubatéSP: Universidade de Taubaté, 2002.

MARTINS; P. ALT, R. Administração de materiais e recursos patrimoniais. São Paulo: Saraiva, 2000.

MATTOS, A. D. Planejamento e controle de obras. São Paulo: Pini, 2010.

VIANA, J. Administração de Materiais: um enfoque prático. São Paulo; Atlas, 2002.

VIEIRA FILHO, G. Gestão da Qualidade Total: uma abordagem prática. 3. ed. Campinas, 2010 . 
APÊNDICE A - RNC preenchida com a identificação e registro da não conforme

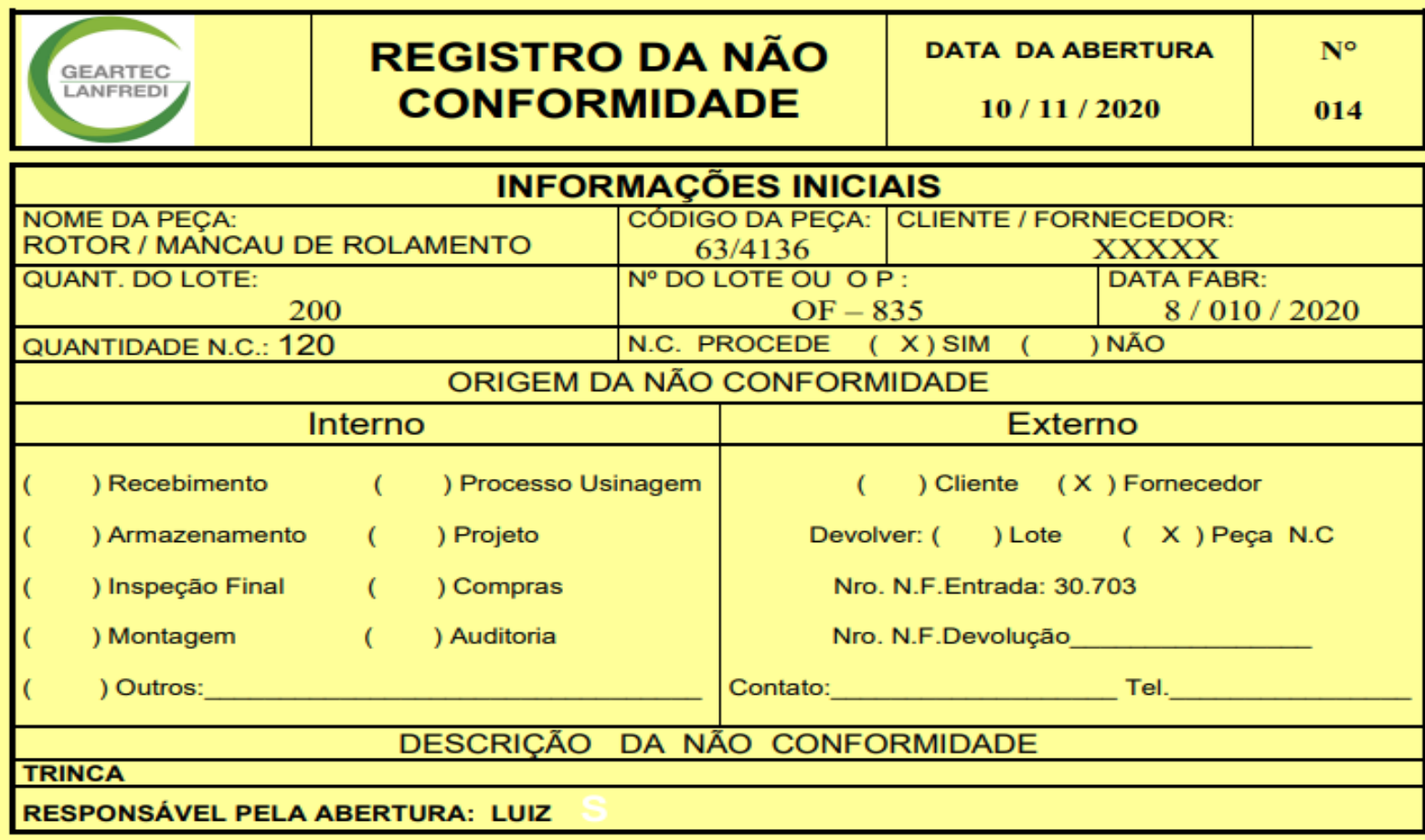

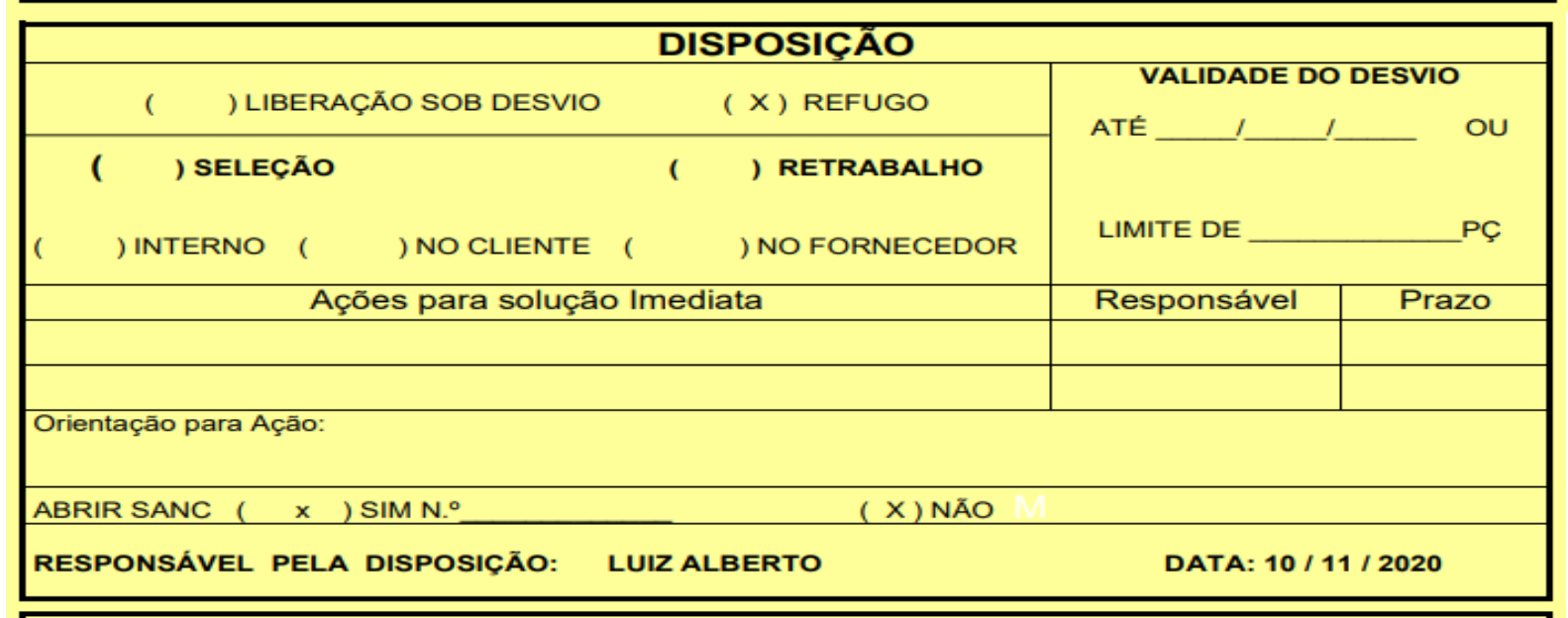

\section{RESPONSÁVEL DA QUALIDADE}

ASSINATURA : LUIZ ALBERTO

Fonte: Autoria própria 
APÊNDICE B - SANC não conformidade externa

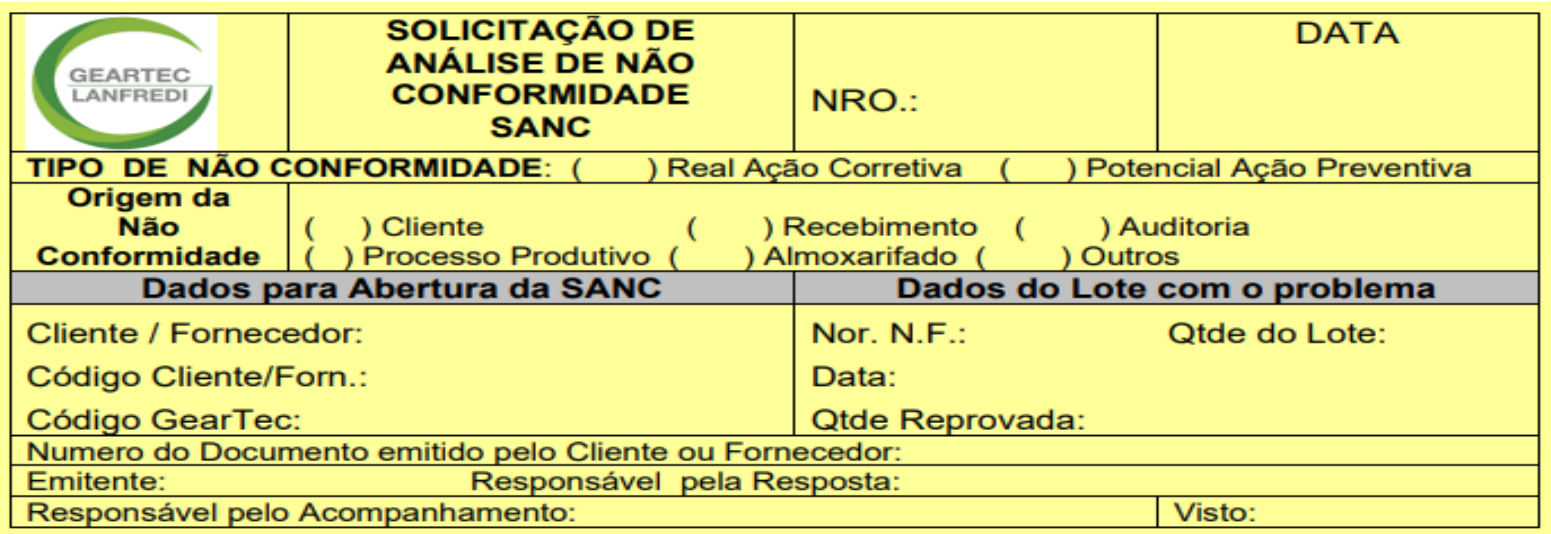

DESCRIÇÃO DA NÃO CONFORMIDADE

CAUSA PRIMARIA

CAUSA PRIMARIA

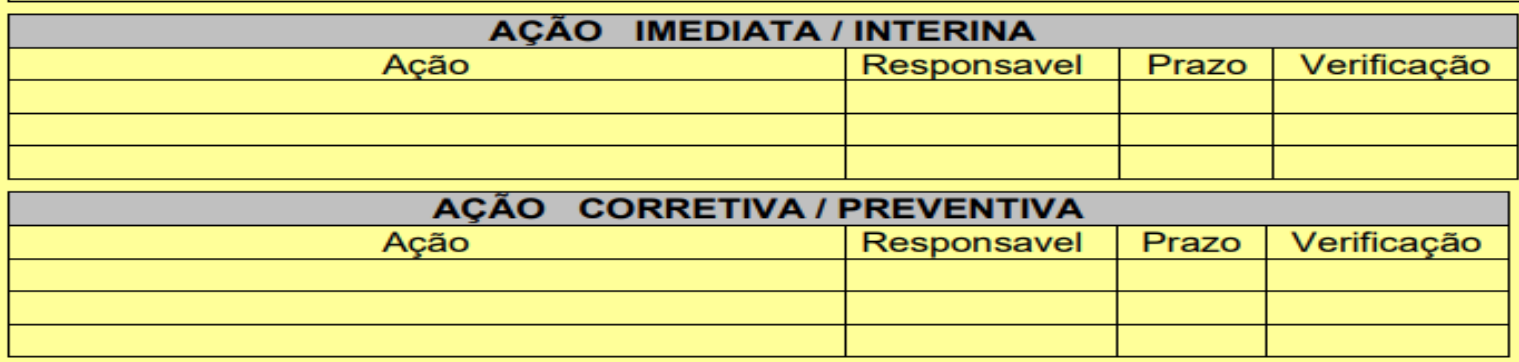

\begin{tabular}{|c|l|l|l|}
\hline EXTENSÃO DAS AÇOES CORRETIVAS / PREVENTIVAS \\
\hline Ação & Responsavel & Prazo & Verificação \\
\hline & & & \\
\hline & & & \\
\hline
\end{tabular}

\begin{tabular}{|c|c|c|c|c|}
\hline Ações Adicionais: ( & ) Revisar processo ( & ) Revisar FMEA & ( & Responsável \\
\hline
\end{tabular}

ACOMPANHAMENTO DOS RESULTADOS

\begin{tabular}{l|l|l} 
Atividade & Responsavel & Data
\end{tabular}

Fonte: Autoria própria 